University of New Haven

University of

New Haven

Digital Commons@ New Haven

Civil Engineering Faculty Publications

Civil Engineering

2015

\title{
Enhanced Electrokinetic Transport of Sulfate in Saline Soil
}

Sung-Ung Jo

Ecophile Co. Ltd, Seoul

Yeon-Jun Shin

Chonbuk National University

Jung-Seok Yang

KIST-Gangneung Institute, Gangneung, Korea

Deok-Hyun Moon

Chosun University

Agamemnon Koutsospyros

University of New Haven, akoutsospyros@newhaven.edu

See next page for additional authors

Follow this and additional works at: http://digitalcommons.newhaven.edu/civilengineering-facpubs Cart of the Civil Engineering Commons

\section{Publisher Citation}

Jo, S., Shin, Y. J., Yang, J. S., Moon, D. H., Koutsospyros, A., \& Baek, K. (2015). Enhanced Electrokinetic Transport of Sulfate in Saline Soil. Water, Air, \& Soil Pollution, 226(6), 1-8.

\section{Comments}

This is the authors' accepted version of the article published in Water, Air \& Soil Pollution. The final publication is available at Springer via http://dx.doi.org/10.1007/s11270-015-2459-6 


\section{Authors}

Sung-Ung Jo, Yeon-Jun Shin, Jung-Seok Yang, Deok-Hyun Moon, Agamemnon Koutsospyros, and Ki-Tae Baek 
Enhanced-Electrokinetic Transport of Sulfate in Saline Soil

SungUng Jo a, Yeon-Jun Shin ${ }^{\mathrm{b}}$, Jung-Seok Yang ${ }^{\mathrm{c}}$, Deok Hyun Moon ${ }^{\mathrm{d}}$, Agamemnon Koutsospyros ${ }^{\mathrm{e}}$, Kitae Baek ${ }^{\text {b,f* }}$

${ }^{a}$ Ecophile.Co. Ltd., Jichang Bldg, 265-26 Yangjae-dong, Seocho-gu, Seoul 137-130, Republic of Korea

${ }^{\mathrm{b}}$ Department of Environmental Engineering, Chonbuk National University, 567 Baekje-daero, Deokjin-gu, Jeonju, Jeollabukdo, Republic of Korea

${ }^{c}$ KIST-Gangneung Institute, Gangneung, Kangwon, Republic of Korea

${ }^{d}$ Department of Environmental Engineering, Chosun University, Gwangju 501-759, Republic of Korea

${ }^{\mathrm{e}}$ Mechanical, Civil and Environmental Engineering, University of New Haven, West Haven, CT 06516, USA

${ }^{\mathrm{f}}$ Department of Bioactive Material Sciences, Chonbuk National University, 567 Baekje-daero, Deokjin-gu, Jeonju Jeollabuk-do, Republic of Korea

*Corresponding author (K.Baek)

Tel.++82-63-270-2437; Fax:+82-63-270-2449; E-mail: kbaek@.jbnu.ac.kr

\section{Abstract}

The electrokinetic transport of sulfate was investigated as a means of treating and restoring a sulfateaccumulating saline soil. The electrokinetic treatment decreased the electrical conductivity of the soil, an indicator of soil salinity, to $58.6 \%, 73.1 \%$, and $83.5 \%$ for 7,14 and 21 days, respectively. More than $96 \%$ of the chloride and nitrate were removed within 7 days. However, the removal of sulfate was highly influenced by the anode material. An iron anode removed sulfate effectively, whereas, sulfate was hyper-accumulated in the anodic region when an inert anode was used. The iron anode was oxidized in a sacrificial anodic reaction, which competed with the electrolysis reaction of water at the anode, and finally the reaction prevented the severe acidification of the soil in the anodic region. However, the competing reactions produced hydrogen ions at the anode, and the ions were transported toward the cathode, which, in turn, acidified the soil, especially, in the anodic region. The acidification switched the surface charge of the soil from negative to positive, increasing the interaction between the soil surface and sulfate, and thus inhibiting the transport of sulfate under the electric field. The zeta potential 
analysis of the soil provided an explanation. The results indicate that preventing severe acidification is an important factor which influences the transport of anions and iron anode for the enhanced removal of anionic pollutants by electrokinetic remediation.

Keywords: sulfate, saline soil, electrokinetic remediation, iron anode, zeta potential

\section{Introduction}

Electrokinetic remediation (EKR) has received attention because it is an in-situ remediation technique applicable to low permeability soils (Kim et al., 2013a; Kim et al., 2014; Kim et al., 2012c). The technique has been used to remove metals (Kim et al., 2012d), organic pollutants (Jeon et al., 2010; Park et al., 2009), and ionic pollutants(Cho et al., 2012; Hamdan et al., 2014; Jo et al., 2012; Kim et al., 2012a; Kim et al., 2013c; Kim et al., 2012b; Ottosen and Rorig-Dalgard, 2007) from contaminated soils, sediments, and sludge. Especially, EKR has been used for the removal of metals and inorganic contaminants from low permeability soils because of the great migration potential of ionic species under the influence of electric fields (Acar and Alshawabkeh, 1993; Acar et al., 1995; Kamran et al., 2013; Ottosen and Rorig-Dalgard, 2007). Electro-kinetic removal of ionic compounds has been demonstrated in various systems ranging from laboratory to pilot and full scale in ex-situ and in-situ remedial schemes. The removal mechanisms that transpire during electro-kinetic removal of ionic materials include electro-migration, electro-osmosis and electro-osmotic flow (Acar et al., 1995). Most researchers have suggested that the major transport mechanism for ionic matter is electro-migration (Hamdan et al., 2014). In the case of anions, the direction of electro-migration is toward the anode whereas the general direction of the electro-osmotic flow is toward the cathode. Therefore, the direction of these two transport mechanisms of anions is opposite. However, cations might be transported toward the cathode by electro-migration and electro-osmotic flow, which is in the same direction. Additionally, speciation of cationic metals is highly dependent on soil and pore solution $\mathrm{pH}$ as metal hydroxide formation may result in decreased ionic mobility under electric fields. Consequently, cationic metals can be removed easily at low $\mathrm{pH}$ conditions because of increased solubility, high ionic mobility, and the enhanced 
desorption. However, anionic pollutants can be desorbed at an alkaline $\mathrm{pH}$ condition, therefore, $\mathrm{pH}$ control to basic conditions is essential to increase the removal of anionic pollutants (Khanna et al., 1986; Schonsky et al., 2013; Weaver et al., 1985). Even though pH effects on pollutant desorption have been discussed, the influence of $\mathrm{pH}$ on the re-adsorption of the desorbed pollutants has not been investigated as much as the desorption of metals.

It is well known that solution $\mathrm{pH}$ may affect the surface charge of a solid matrix because of deprotonation or protonation (Nodvin et al., 1986). Especially, clay particles have hydroxyl groups exposed on their surfaces and edges, and the hydroxyl groups can be dissociated in water, which is strongly influenced by solution pH (Cho et al., 2011b; Jung et al., 2011; Yang et al., 2014). At higher $\mathrm{pH}$, the deprotonation reaction is superior, provides $\mathrm{H}^{+}$into solution, and the negative charge of the particle becomes greater. At lower $\mathrm{pH}$, however, the protonation reaction of clay minerals is predominant, therefore, the surface becomes more positive. Therefore, a negatively charged soil surface can enhance the transport of anionic pollutants by electrokinetic remediation, however, the soil surface inhibits the transport of cationic contaminants because of electro-static interaction or repulsion between the charged soil surface and ions. The electro-static interaction or repulsion is proportional to the square of ion valences.

Sulfate is one of anions causing salinization of soil, and the electrokinetic transport of sulfate was retarded compared to nitrate and chloride (Cho et al., 2011a; Jo et al., 2012; Lee et al., 2013b). Researchers explained that the retardation of sulfate transport was caused from the precipitation as insoluble form with some metals. However, the sulfate transport could be influenced by the surface charge of soil, which might be changed due to acidification of soil during the electrokinetic restoration of saline soil.

In this study, we investigated the electrokinetic restoration of saline soil, and focused on the transport of anions including chloride, nitrate, and sulfate. Especially, sulfate transport was highly dependent on the electrode materials, which changed the soil $\mathrm{pH}$.

\section{Materials and Methods}


Saline soil was sampled from a greenhouse in Gumi, Gyeongsangbukdo in the Republic of Korea. The soil was air-dried and sieved with a $2 \mathrm{~mm}$ sieve, and soil with a diameter $<2 \mathrm{~mm}$ was used for the experiments. Initial characteristics of the soil were analyzed and summarized in Table 1. The electrical conductivity of the soil was $8.9 \mathrm{dS} / \mathrm{cm}$, which was 4.5 times higher than the general guideline for cultivation in Korea (Kim et al., 2013b). The soil contained high portions of sulfates as well as nitrates, and calcium was the major exchangeable cation.

Five experiments were performed for the specified durations with an inert anode or a reactive iron anode. A soil sample was added into the electrokinetic soil cell (Figure 1). Experiment 1 used a mesh type of Pt-coated Titanium as an anode, iron plates were used for experiments 2-5 as an anode material, and the cathode material, a mesh type of Pt-coated Titanium, were exactly the same in all experiments. A filter paper was located at the interface between the soil cell and the electrode compartment to prevent soil loss into the compartment and to allow the passage of water or ions. The anode compartment was connected to an anolyte reservoir, and the anolyte was circulated by a peristaltic pump. The cathode compartment was connected to an electro-osmotic flow (EOF) reservoir to measure the volume of EOF. In all experiments, tap water was used as an anolyte and catholyte, to fill the electrode compartments and to adjust initial water content of the soil in the soil cell. The analyte solutions were not refreshed until the end of the experiments. After electrokinetic treatment under $1 \mathrm{~V} / \mathrm{cm}$, soil samples were sliced into 10 equal sections, and used to determine the residual soluble anions, exchangeable cations, final pH and electrical conductivity (EC)(Lee et al., 2013a).

Soil EC and soluble anions were determined according to Korea Standard Test Method (KSTM): dry soil (equivalent to soil dried at $105^{\circ} \mathrm{C}$ ) and deionized water was mixed with ratio of 1: 5 and shaken for $1 \mathrm{~h}$. The mixture was filtered out using a 5B filter paper (Advantec, Japan). A pH meter (Istek 735P, Korea) and conductivity meter (Istek 455C, Korea) were used to measured $\mathrm{pH}$ and EC, respectively. Water soluble anions were analyzed using ion chromatography (Futecs, Korea). Exchangeable cations were determined as follow: $5 \mathrm{~g}$ (equivalent to soil dried at $105^{\circ} \mathrm{C}$ ) of soil sample and $50 \mathrm{ml}$ of $1 \mathrm{~N}$ $\mathrm{NH}_{4} \mathrm{OAc}\left(\mathrm{CH}_{3} \mathrm{COONH}_{4}\right)$ adjusted the $\mathrm{pH}$ to 7 using $\mathrm{CH}_{3} \mathrm{COOH}$ were mixed thoroughly for $1 \mathrm{~h}$. After extraction of exchangeable cations, the filtrate was analyzed using inductively coupled plasma optical 
emission spectrometry (ICP-OES, Varian, USA).

The speciation of inorganic sulfur was determined using the procedure proposed by Shan and his colleagues (Shan et al., 1997). The speciation was classified as waster-soluble sulfate, adsorbed sulfate, and carbonate-occluded sulfate. The sulfate was analyzed using ion chromatography (Futecs, Korea).

\section{Results and Discussions}

\section{Current and electo-osmotic flow}

In electrokinetic remediation, a current under a constant voltage gradient exhibits the typical shape presented in Fig.2-a. Generally, the current increases sharply because of the electrolysis reaction on the electrode, which provides ions to the system. The $\mathrm{H}^{+}$and $\mathrm{OH}^{-}$ions generated by electrolysis reaction are transported toward the oppositely charged electrode, meets in the middle section between the anode and cathode, and finally the conductive ions are removed from the system. That is the major reason for the gradual decrease in the current after initial sharp increase. Additionally, the gradual removal of dissolved salts from the soil caused a current decrease because the dissolved salts in pore water increase the electrical conductivity.

Electro-osmotic flow (EOF) moves from the anode to cathode, and there was not a significant variation in the accumulated EOF (Fig.2-b). The accumulated EOF increased linearly with operational time, which indicates that the EOF was not significantly influenced by the electrode materials. Additionally, we analyzed the relationship between the flow rate of EOF and average current. Actually, the average flow rate of EOF was approximately $12 \mathrm{~mL} /$ day except in Exp.2, where the value was $17.8 \mathrm{ml} /$ day. In Exp.2, the average current was $8.7 \mathrm{~mA}$, and others were approximately $6.0 \mathrm{~mA}$. Therefore, the flow rate of EOF is strongly related with the average current.

\section{pH distribution of soil}

The distribution of soil $\mathrm{pH}$ after the electrokinetic treatment shows the typical pattern associated with electrokinetic remediation, where the anode region is acidic and the cathode region is alkaline. However, the iron anode prevented acidification as compared to the inert anode (Exp.1). The $\mathrm{pH}$ of the anodic 
region was around 2.5 in the inert anode (Exp.1), however, the $\mathrm{pH}$ was around 4.0 in the iron anode (Exp.4 and Exp.5). In addition, the soil acidification propagated toward the cathode with increasing operational time. However, the cathodic $\mathrm{pH}$ was not changed significantly. The iron anode sacrificial reaction competed with the anodic electrolysis reaction which involved the generation of hydrogen ions(Lee et al., 2013a). Therefore, the iron anode generated less amounts of hydrogen ions as compared to the inert anode. It is probable that the anodic reaction of the iron anode produced ferrous ions, but the ions could have been oxidized to ferric ions, and the ferric ion easily forms a solid ferric hydroxide precipitate, as a result of the reaction with water. Finally, the precipitation reaction produced hydrogen ions, which decreased the $\mathrm{pH}$ (Makino et al., 2008). That is the reason behind the gradual decrease and propagation of hydrogen ions with increasing operational time.

$$
\begin{aligned}
& 2 \mathrm{H}_{2} \mathrm{O} \rightarrow 4 \mathrm{H}^{+}+\mathrm{O}_{2}(g) \\
& \mathrm{Fe} \rightarrow \mathrm{Fe}^{2+}+2 \mathrm{e}^{-} \\
& 4 \mathrm{Fe}^{2+}+\mathrm{O}_{2}+4 \mathrm{H}^{+} \rightarrow 4 \mathrm{Fe}^{3+}+2 \mathrm{H}_{2} \mathrm{O} \\
& \mathrm{Fe}^{3+}+3 \mathrm{H}_{2} \mathrm{O} \rightarrow \mathrm{Fe}(\mathrm{OH})_{3}(s)+3 \mathrm{H}^{+}
\end{aligned}
$$

\section{Changes in electrical conductivity of soil}

Fig. 3 shows the distribution of the electrical conductivity of the soil after the electrokinetic treatment. EC is an indicator for salt accumulation in soil. As shown in the Fig.3, in the case of the iron anode, the soil EC decreased gradually with operational time, and the EC was highest in the middle section of the soil. The soluble anions including chloride, nitrate, and sulfate move toward the anode, while the exchangeable cations move toward the cathode. The water soluble anions such as chloride and nitrate have less interaction with the soil particles. Therefore the transport rate is faster than for divalent cations. This explains the higher EC in the middle section of the soil. As the operational time increases, the anions move toward the anode and the EC decreases gradually. We use deionized water to extract watersoluble ions for the analysis of soil EC. The gradual decrease in soil EC indicates that the water soluble ions are removed from the soil. However, in Exp. 1 with an inert anode, EC was hyper-accumulated in the anodic region. We analyzed the water soluble anions in the soil to investigate the reason for the 
hyper accumulation.

\section{Distribution of soluble anions and exchangeable cations}

As shown in Fig.4, chloride and nitrate were removed almost completely from the soil even though there was variation in the removal rate in each experimental condition. Chloride and nitrate are major contributors to soil EC, however, the water soluble concentration was negligible. The concentration of sulfate was totally different from the concentrations of chloride and nitrate (Fig. 4-c). The EC and sulfate distribution profiles were virtually identical, which indicates that the soil EC was influenced significantly by the residual concentration of water soluble sulfate in the soil. The sulfate was gradually removed from the soil with increasing operational time, when an iron anode was used. Conversely, sulfate accumulated in the anodic region with an inert anode. Additionally, exchangeable cations were not completely extracted by the deionized water. Therefore, the exchangeable cations contributed less to the soil EC as compared to the water soluble anions. The exchangeable cations such as potassium, calcium, and magnesium were transported toward the cathode as shown in Fig. 5. Consequently, the concentration of exchangeable cations decreased in the anodic region and increased in the cathodic region. However, sodium was removed completely from the soil by the electrokinetic treatment.

\section{Speciation analysis of inorganic sulfur}

To investigate the speciation of inorganic sulfur, we analyzed the inorganic sulfur into three categories: water soluble inorganic sulfur (mainly sulfate), adsorbed sulfur, and carbonate-occluded sulfur. Sulfur speciation profiles throughout the EK cell length are shown in Fig. 6. Evidently, when the iron anode was used, the speciation of sulfur was similar regardless of the normalized distance. This indicates that the sulfur was not transformed and was removed from the soil. However, in case of the inert anode, the water soluble form of sulfur accumulated at the anodic region, especially from the 0.3 region to the anode. Therefore, sulfur accumulated in the soil in the form of sulfate, which means that the sulfate was transported toward the anode and accumulated at the 0.3 region from anode. To investigate the mechanism of sulfate accumulation, we focused on the soil $\mathrm{pH}$ in the anodic region. As mentioned 
previously, the iron anode prevented the severe acidification of soil in the anodic region, especially from the anode to 0.3 of the normalized distance. It is postulated that the acidification changed the surface charge of the soil from negative to positive because of the adsorption of protons to the soil surface. The positively charged soil surface enhanced the interaction between the soil surface and the sulfate. In addition, the sulfate was hyper-accumulated in that region. Zeta-potential measurements, shown in Fig. 7 indicate that the original soil and the soil treated by the iron anode have a negatively charged surface across the whole $\mathrm{pH}$ range. On the other hand, the surface charge in the soil treated by the inert anode changed from negative to positive below a $\mathrm{pH}$ of 2.6, which increased the interaction between the soil surface and sulfate, and finally inhibited the electrokinetic transport of sulfate. The zeta potential could be evidence that suggests the surface charge hypothesis.

\section{Conclusions}

The authors investigated iron anode-enhanced electrokinetic remediation to remove sulfate. Both the iron anode and the inert anode removed the chloride and nitrate completely within a short time. However, sulfate removal was retarded as compared to that of chloride and nitrate, and increased with operational time. In the case of the inert anode, the sulfate accumulated in the anodic region, whereas the iron anode removed sulfate from the soil. The iron anode prevented severe acidification of the soil because the iron anode sacrificial reaction competed with the electrolysis reaction of water. The main contribution of the iron anode involved a reduction of the hydrogen ions produced. Additionally, the acidification of the soil changed the surface charge of the soil from negative to positive, which significantly increased the electrostatic interaction between the soil surface and sulfate. The reduction of acidification associated with the iron anode enhanced sulfate removal.

\section{Acknowledgements}

This work was supported by KEITI through the GAIA project.

\section{References}


Acar, Y. B. \& Alshawabkeh, A. N.: 1993, 'Principles of electrokinetic remediation', Environ Sci Technol 27, 2638-2647.

Acar, Y. B., Gale, R. J., Alshawabkeh, A. N., Marks, R. E., Puppala, S., Bricka, M. \& Parker, R.: 1995, 'Electrokinetic remediation: Basics and technology status', J Hazard Mater 40, 117-137.

Cho, J. M., Kim, D. H., Yang, J. S. \& Baek, K.: 2011a, 'Electrokinetic Restoration of SulfateAccumulated Saline Greenhouse Soil', Clean-Soil Air Water 39, 1036-1040.

Cho, J. M., Kim, D. H., Yang, J. S. \& Baek, K.: 2011b, 'Electrokinetic Restoration of SulfateAccumulated Saline Greenhouse Soil', CLEAN-Soil, Air, Water 39, 1036-1040.

Cho, J. M., Kim, D. H., Yang, J. S. \& Baek, K.: 2012, 'Electrode Configuration for Electrokinetic Restoration of Greenhouse Saline Soil', Sep Sci Technol 47, 1677-1681.

Hamdan, S. H., Molelekwa, G. F. \& Van der Bruggen, B.: 2014, 'Electrokinetic Remediation Technique: An Integrated Approach to Finding New Strategies for Restoration of Saline Soil and to Control Seawater Intrusion', Chemelectrochem 1, 1104-1117.

Jeon, C. S., Yang, J. S., Kim, K. J. \& Baek, K.: 2010, 'Electrokinetic Removal of Petroleum Hydrocarbon from Residual Clayey Soil Following a Washing Process', Clean-Soil Air Water 38, 189193.

Jo, S. U., Kim, D. H., Yang, J. S. \& Baek, K.: 2012, 'Pulse-enhanced electrokinetic restoration of sulfatecontaining saline greenhouse soil', Electrochim Acta 86, 57-62.

Jung, K., Ok, Y. S. \& Chang, S. X.: 2011, 'Sulfate adsorption properties of acid-sensitive soils in the Athabasca oil sands region in Alberta, Canada', Chemosphere 84, 457-463.

Kamran, K., van Soestbergen, M. \& Pel, L.: 2013, 'Electrokinetic Salt Removal from Porous Building Materials Using Ion Exchange Membranes', Transport Porous Med 96, 221-235.

Khanna, P. K., Weaver, G. T. \& Beese, F.: 1986, 'Effect of Sulfate on Ionic Transport and Balance in a Slightly Acidic Forest Soil', Soil Sci Soc Am J 50, 770-776.

Kim, B. K., Park, G. Y., Jeon, E. K., Jung, J. M., Jung, H. B., Ko, S. H. \& Baek, K.: 2013a, 'Field Application of In Situ Electrokinetic Remediation for As-, Cu-, and Pb-Contaminated Paddy Soil', Water Air Soil Poll 224, 1698.

Kim, D.-H., Jo, S.-U., Yoo, J.-C. \& Baek, K.: 2013b, ' Ex situ pilot scale electrokinetic restoration of saline soil using pulsed current', Sep Purif Technol 120, 282-288.

Kim, D. H., Jo, S. U., Choi, J. H., Yang, J. S. \& Baek, K.: 2012a, 'Hexagonal two dimensional electrokinetic systems for restoration of saline agricultural lands: A pilot study', Chem Eng J 198, 110121.

Kim, D. H., Jo, S. U., Yoo, J. C. \& Baek, K.: 2013c, 'Ex situ pilot scale electrokinetic restoration of saline soil using pulsed current', Sep Purif Technol 120, 282-288.

Kim, D. H., Jung, J. M., Jo, S. U., Kim, W. S. \& Baek, K.: 2012b, 'Photovoltaic Powered Electrokinetic Restoration of Saline Soil', Sep Sci Technol 47, 2235-2240.

Kim, W. S., Jeon, E. K., Jung, J. M., Jung, H. B., Ko, S. H., Seo, C. I. \& Baek, K.: 2014, 'Field application of electrokinetic remediation for multi-metal contaminated paddy soil using twodimensional electrode configuration', Environ Sci Pollut R 21, 4482-4491.

Kim, W. S., Park, G. Y., Kim, D. H., Jung, H. B., Ko, S. H. \& Baek, K.: 2012c, 'In situ field scale electrokinetic remediation of multi-metals contaminated paddy soil: Influence of electrode configuration', Electrochim Acta 86, 89-95.

Kim, Y. H., Kim, D. H., Jung, H. B., Hwang, B. R., Ko, S. H. \& Baek, K.: 2012d, 'Pilot Scale Ex-Situ Electrokinetic Remediation of Arsenic-Contaminated Soil', Sep Sci Technol 47, 2230-2234.

Lee, Y.-J., Choi, J.-H., Lee, H.-G. \& Ha, T.-H.: 2013a, 'In Situ Electrokinetic Removal of Salts from Greenhouse Soil Using Iron Electrode', Sep Sci Technol 48, 749-756.

Lee, Y. J., Choi, J. H., Lee, H. G. \& Ha, T. H.: 2013b, 'Electrokinetic Remediation of Saline Soil Using Pulse Power', Environ Eng Sci 30, 133-141.

Makino, T., Takano, H., Kamiya, T., Itou, T., Sekiya, N., Inahara, M. \& Sakurai, Y.: 2008, 'Restoration of cadmium-contaminated paddy soils by washing with ferric chloride: $\mathrm{Cd}$ extraction mechanism and bench-scale verification', Chemosphere 70, 1035-1043.

Nodvin, S. C., Driscoll, C. T. \& Likens, G. E.: 1986, 'The effect of pH on sulfate adsorption by a forest soil', Soil Sci 142, 69-75. 
Ottosen, L. M. \& Rorig-Dalgard, I.: 2007, 'Electrokinetic removal of $\mathrm{Ca}(\mathrm{NO} 3)(2)$ from bricks to avoid salt-induced decay', Electrochim Acta 52, 3454-3463.

Park, S. W., Lee, J. Y., Yang, J. S., Kim, Y. J. \& Baek, K.: 2009, 'Electrokinetic remediation of contaminated soil with waste-lubricant oils and zinc', J Hazard Mater 169, 1168-1172.

Schonsky, H., Peters, A., Lang, F., Abel, S., Mekiffer, B. \& Wessolek, G.: 2013, 'Sulfate transport and release in technogenic soil substrates: experiments and numerical modeling', J Soil Sediment 13, 606615.

Shan, X.-Q., Chen, B., Zhang, T.-H., Li, F.-L., Wen, B. \& Qian, J.: 1997, 'Relationship between sulfur speciation in soils and plant availability', Science of the total environment 199, 237-246.

Weaver, G. T., Khanna, P. K. \& Beese, F.: 1985, 'Retention and Transport of Sulfate in a Slightly Acid Forest Soil', Soil Sci Soc Am J 49, 746-750.

Yang, J.-S., Kwon, M. J., Choi, J., Baek, K. \& O’Loughlin, E. J.: 2014, 'The transport behavior of As, $\mathrm{Cu}, \mathrm{Pb}$, and $\mathrm{Zn}$ during electrokinetic remediation of a contaminated soil using electrolyte conditioning', Chemosphere 117, 79-86. 
Figure Captions

Fig.1. Schematic diagram for the electrokinetic experimental apparatus

Fig.2. Current (a) and accumulated electro-osmotic flow (b) during the electrokineic treatment

Fig.3. Distribution of $\mathrm{pH}$ (a) and electrical conductivity (b) after the electrokinetic treatment

Fig.4 Distribution of water soluble chloride (a) nitrate (b), and sulfate (c) after the electrokinetic treatment

Fig.5 Distribution of exchangeable Calcium (a), Magnesium (b), Potassium (c), and Sodium (d) after the electrokinetic treatment

Fig.6. Fractionation of inorganic sulfur after the electrokinetic treatment. (a) iron anode during 21 days (Exp.4), (b) inert anode during 21 days (Exp.1)

Fig.7. Zeta potential of soil in the anodic region according to equilibrium $\mathrm{pH}$ 


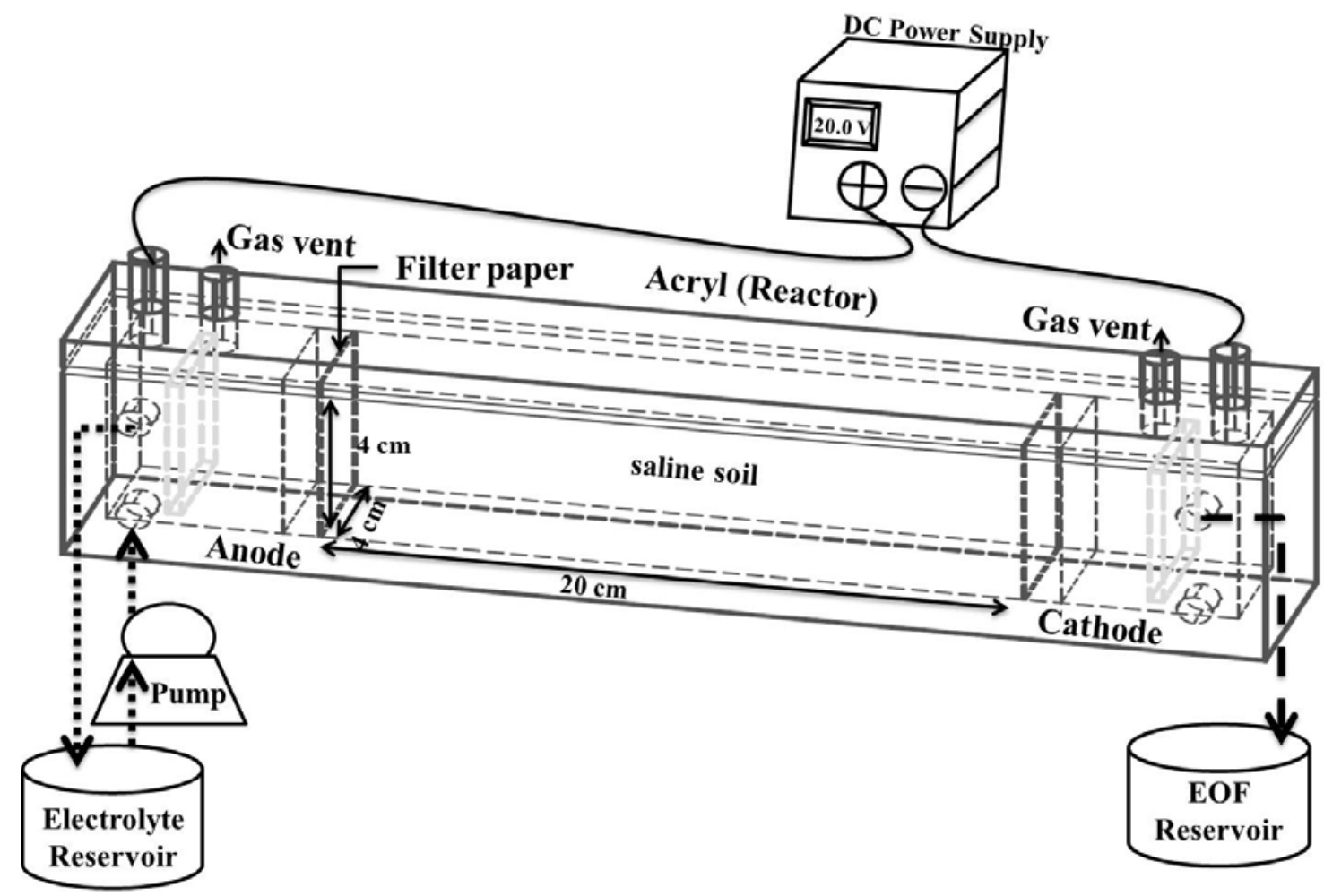

Figure.1 


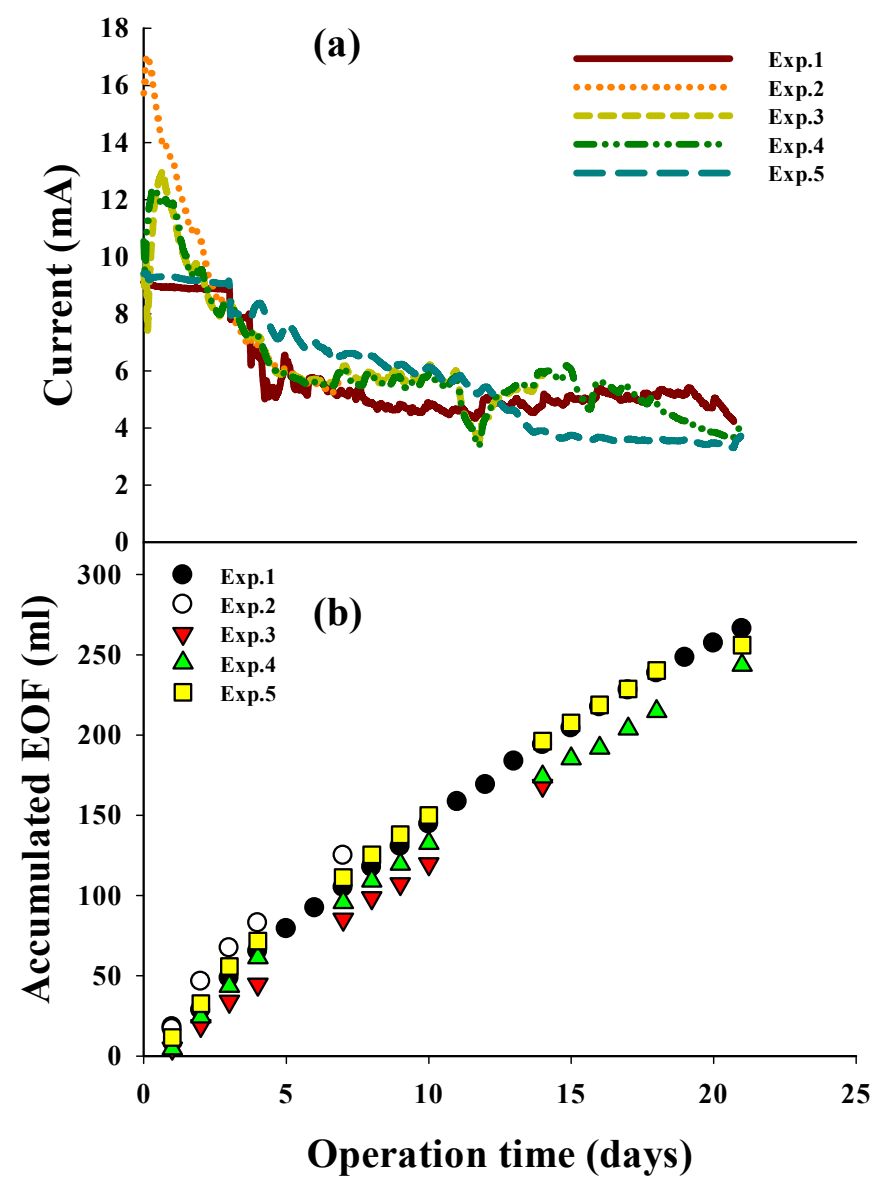

Figure 2 


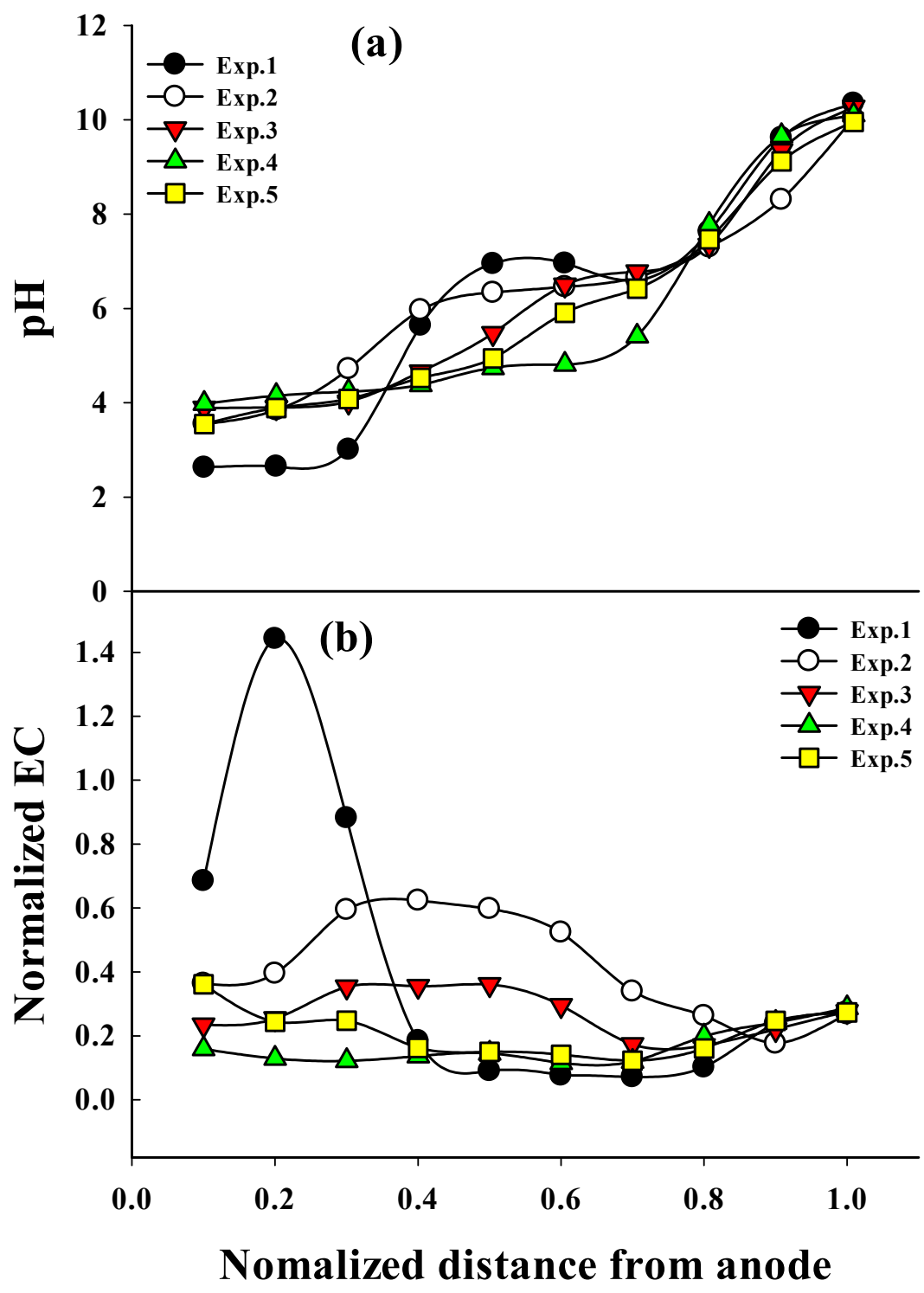

Figure 3 


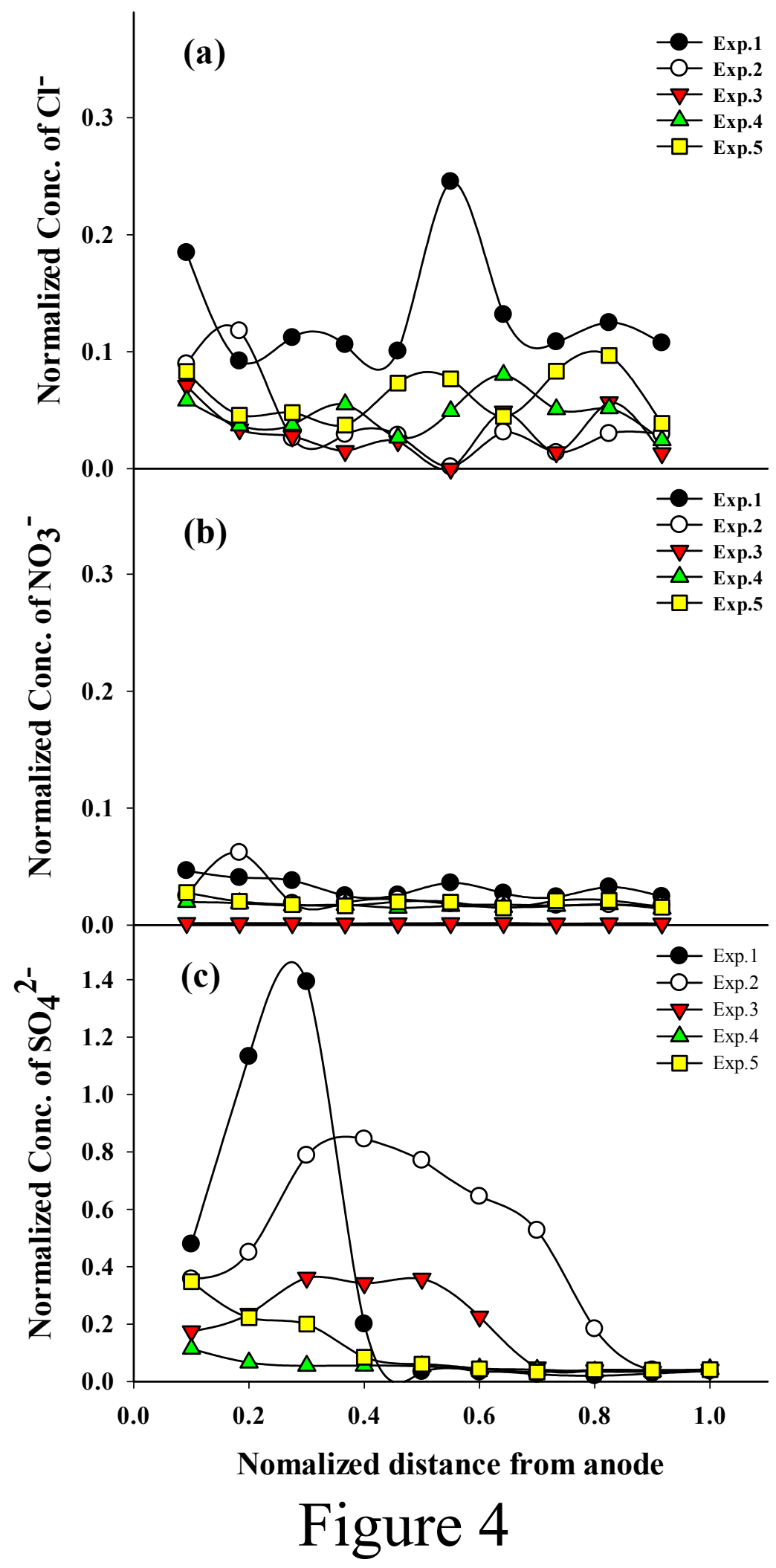




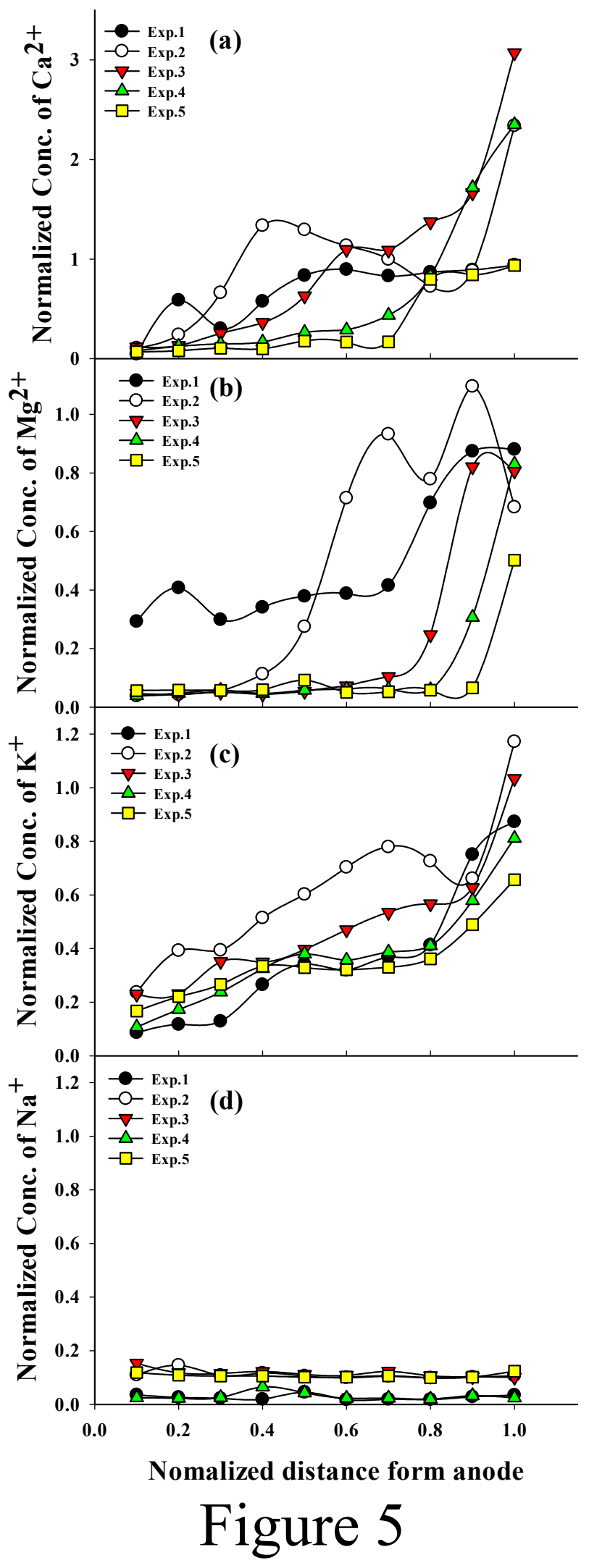




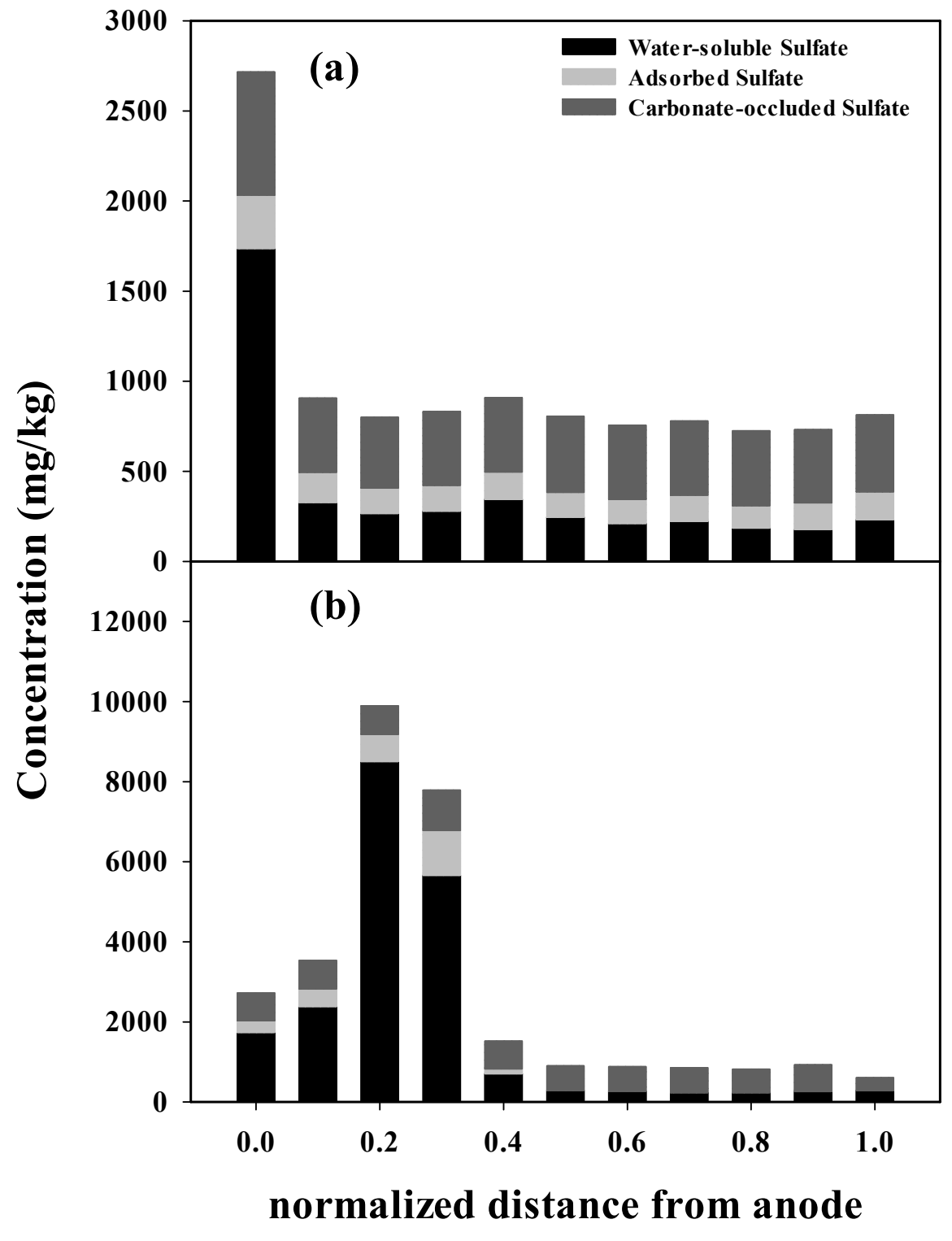

Figure 6 


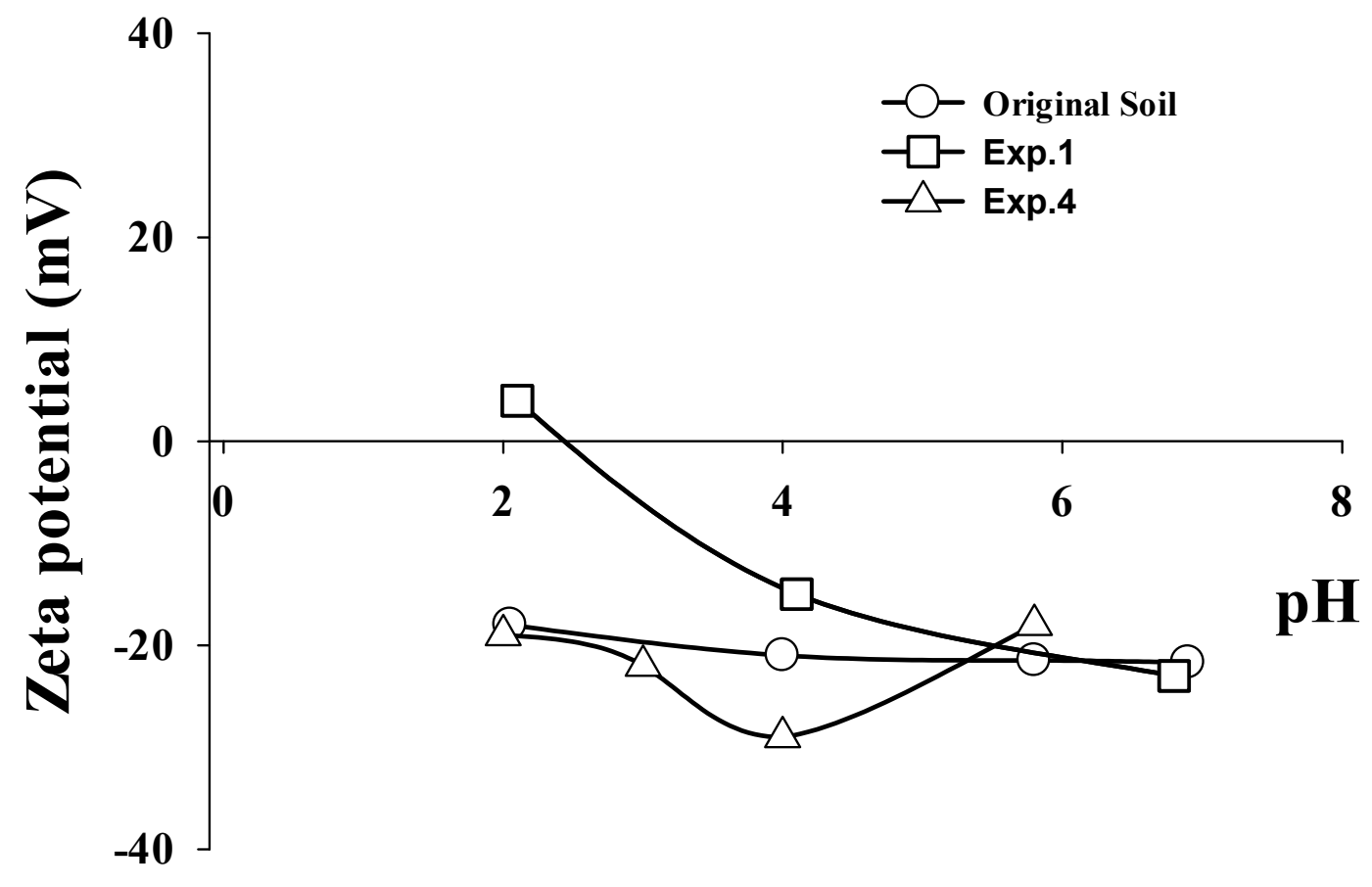

Figure 7 
Table.1 Physico-chemical properties of soil

\begin{tabular}{ll}
\hline characteristic & value \\
\hline $\mathrm{pH}$ & 6.4 \\
$\mathrm{EC}(\mathrm{dS} / \mathrm{m})$ & 8.9 \\
Organic matter content $(\%)$ & 9.03 \\
Initial concentration $(\mathrm{mg} / \mathrm{kg})$ & \\
$\mathrm{Cl}^{-}$ & 346 \\
$\mathrm{NO}_{3}{ }^{-}$ & 1763 \\
$\mathrm{SO}_{4}^{2-}$ & 3742 \\
$\mathrm{Ca}^{2+}$ & 3940 \\
$\mathrm{~K}^{+}$ & 879 \\
$\mathrm{Mg}^{2+}$ & 619 \\
$\mathrm{Na}^{+}$ & 1260 \\
\hline
\end{tabular}

Table 2. Removal efficiency of salts in soil after the electrokinetic restoration.

\begin{tabular}{cccccc}
\hline Exp. No & $\begin{array}{c}\text { Anode } \\
\text { Materials }\end{array}$ & $\begin{array}{c}\text { Cathode } \\
\text { Materials }\end{array}$ & $\begin{array}{c}\text { Operation } \\
\text { Time } \\
(\text { days })\end{array}$ & $\begin{array}{c}\text { Voltage } \\
\text { gradient } \\
(\mathrm{V} / \mathrm{cm})\end{array}$ & $\mathrm{SO}_{4}{ }^{2-}$ Removal (\%) \\
\hline Exp.1 & Iridium-coated Ti & & 21 & & 66.2 \\
Exp.2 & $\mathrm{Fe}$ & & 7 & & 53.6 \\
Exp.3 & $\mathrm{Fe}$ & Iridium-coated Ti & 14 & 1 & 81.4 \\
Exp.4 & $\mathrm{Fe}$ & & 21 & & 94.6 \\
Exp.5 & $\mathrm{Fe}$ & 21 & & 88.8 \\
\hline
\end{tabular}

